Review Article

\title{
Acquired Childhood Dysarthria: Review of Its Clinical Presentation
}

\author{
Marijke van Mourik, MA*t, Coriene E. Catsman-Berrevoets, MD, PhD*, \\ Phillipe F. Paquier, $\mathbb{P h D}^{* s}$, Ellen Yousef-Bak, $\mathbf{B A}^{*}$, and Hugo $\mathbb{R}$. van Dongen, $\mathrm{PhD}^{*}$
}

The adult classification of dysarthria correlating with the pathophysiology of the motor systems is usually applied to classify acquired childhood dysarthria. However, the validity of this adult model for children has not been studied systematically. All studies pertaining to analysis of speech features in acquired childhood dysarthria published since 1980 were reviewed. Studies were classified on the basis of neuroradiologic evidence of lesion site and associated motor disorder. This review demonstrates that knowledge of acquired childhood dysarthria is based on a limited number of single case studies, most of which pertain to dysarthria occurring after resection of cerebellar tumor. Definite similarities to adult dysarthria were not evident. Some similarity to acquired childhood dysarthria due to basal ganglia lesions was detected. We conclude that acquired childhood dysarthria requires its own classification. (1) 1997 by Elsevier Science Inc. All rights reserved.

van Mourik M, Catsman-Berrevoets CE, Payuier PF. Yousef-Bak E, van Dongen HR. Acquired childhood dysarthria: Review of its clinical presentation. Pediatr Neurol 1997:17:299-307.

\section{Introduction}

Dysarthria is a motor speech deficit in neurologic disorders. Rate, strength, and coordination of the muscles subserving speech may be impaired to different degrees, affecting articulation, prosody, resonance, respiration, and phonation. Darley et al. [1,2] analyzed speech in 212 adult patients. Deviant speech features occurred in clusters. characterizing major types of dysarthria in adults: ataxic, flaccid, hypokinetic, hyperkinetic, and spastic. The most distinct features of each type, as presented by Darley et al. [2] are presented in Table 1. Darley et al. [1,2] concluded that these distinctive patterns have localizing value and can assist in identifying the underlying neuropathology, as the deviant specch features mirrored the kind of motor disorder in limbs and trunk.

Other studies in adults have modified the list of prominent speech features, mainly for ataxic dysarthria [3-6]. Enderby et al. [7] criticized the typology of dysarthria because pyramidal and corticospinal tracts are modulated by extrapyramidal and cerebellar circuitry prior to excitation of the final common pathways. Consequently, similarities between dysarthrias with different lesions are expected. Despite this criticism, the "adult model" of distinct dysarthria types $[1,2]$ and their correlation with pathophysiology are widely accepted.

Acquired childhood dysarthria $(A C D)^{\text {:k }}$ is certainly not a rare disorder, although its overall incidence or its prevalence in pediatric neurology is not known. Despite its frequent occurrence in the pediatric population, ACD has hardly been studied systematically. Most pediatric studies merely report its presence or frequency within the context of a specific neurologic condition. Other pediatric studies refer to dysarthria in terms of underlying motor disorder (spastic, ataxic) or neuroanatomic site of damage (cerebellar, bulbar), but provide no systematic analysis of the speech features. Thus, these studies implicitly assume the

* For the purpose of the present study. we define ACD as a motor speech disorder due to brain lesions acyuired in childhood after normal onset of speech development. We exclude speech disorders in developmental and degenerative disorders.
From the *Department of Neurology: University Hospital and Erasmus University; Rotterdam: 'Department of Medical Psychology: Tiekenhuis Walcheren Vlissingen: Vlissingen: The Netherlands:

Division of Applied Neurolinguistics: Department of ENT Surgery:

School of Medicine: University of Antwerp (UIA): Antwerp: and

Department of Neurology: University Hospital Erasme; Free

University of Brussels (ULB): Brussels. Belgium.
Communications should be addressed to:

Dr. van Mourik; Department of Medical l'sychology/Ziekenhuis

Walcheren: Postbus 3200; 4380 DD Vlissingen. The Netherlands.

Received Octoher 21. 1996: accepted December 6. 1996. 
Table 1. Comparison of features in adult dysarthria types with pediatric cases

\begin{tabular}{|c|c|}
\hline $\begin{array}{l}\text { Most Distinctive Speech Features in } \\
\text { Adult Dysarthria Types [2] }\end{array}$ & $\begin{array}{c}\text { Studies Reporting } \\
\text { Features in } \\
\text { Children }\end{array}$ \\
\hline \multicolumn{2}{|l|}{ Ataxic dysarthria } \\
\hline Irregular breakdown of articulation & $\{17\}$ \\
\hline Excess and equal stress & $|14.23|$ \\
\hline Prolongations of phonemes and intervals & —* \\
\hline Slow rate & {$[1,3,15.17-19.21,22]$} \\
\hline Harsh voice & —* \\
\hline Monotomy & {$[12,13,15,19]$} \\
\hline \multicolumn{2}{|l|}{ Flaccid dysarthria } \\
\hline Hypernasality & $|25|$ \\
\hline Nasal emission of air & 一" \\
\hline Continuous breathiness & {$[25]$} \\
\hline Audible inspiration & —* \\
\hline \multicolumn{2}{|l|}{ Hypokinetic dysarthria } \\
\hline Monopitch & - * \\
\hline Mono-loudness & —: \\
\hline Hypophonia & 一" \\
\hline Imprecise articulation & {$[33,35,36]$} \\
\hline Variable rate & {$[3,3,35 \mid$} \\
\hline Short bursts of speech (stuttering) & $\mid 33.35\}$ \\
\hline \multicolumn{2}{|l|}{ Quick hyperkinetic dysarthrial (chorea) } \\
\hline Hypernasality & $\ldots$ \\
\hline Harshness & $\ldots$ \\
\hline Breathiness & _- * \\
\hline Loudness variations & -* \\
\hline \multicolumn{2}{|l|}{ Slow hyperkinetic dysarthria (dystonia) } \\
\hline Imprecise articulation & [34] \\
\hline Hypophonia & $|.34,35|$ \\
\hline Variable rate & $--^{*}$ \\
\hline Harshness plus strained strangled voice & -** \\
\hline $\begin{array}{l}\text { Transient breathiness plus audible } \\
\text { Inspiration }\end{array}$ & $-*$ \\
\hline \multicolumn{2}{|l|}{ Spastic dysarthria } \\
\hline Imprecise articulation & $\ldots$ \\
\hline Slow rate & $\ldots$ \\
\hline Low pitch & 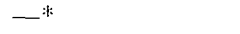 \\
\hline Harsh voice & $\ldots *$ \\
\hline Strained strangled voice & $-\ldots$ \\
\hline Pitch breaks & _- * \\
\hline Reduced stress & - \\
\hline
\end{tabular}

appropriateness of the adult model of dysarthria for children.

Therefore, we (a) surveyed the literature on speech features in ACD in relation to lesion site and motor dysfunction in order to discuss the validity of the adult model, i.e., the existence of distinct dysarthria types in childhood; and (b) reviewed studies in which the analysis of ACD is of importance for clinicai management.

Inclusion and exclusion criteria were as follows. First. we searched Medline databases from 1980 to 1996 for publications available in English under the search strategies "dysarthria" or "speech disorders." We selected, reviewed, and analyzed studies pertaining to acquired dysarthria. Second, we included only descriptions of children aged 16 years or less. Third, we included studies mentioning perceptual judgment of speech features (ac- cording to the Mayo Clinic List $[1,2]$ ) soon after onset of the speech problem. These speech features are indicated by quotations in the text. These studies are summarized in Tables 2 to 5. To illustrate a clinical context in which ACD may occur, we sometimes refer to cases with nonspecifi: indications such as "slurred" or "dragged" speech, but these cases are not included in Tables 2 to 5. Fourth, cases were excluded when the speech disorder was a mixture of dysarthria and aphasia or verbal apraxia, as this obscures the very nature of the dysarthria. (For differential diagnostic issues, we refer to othar studies [8-10].) We classified on the basis of neuroradiologic evidence of lesion site and associated motor disorder, tiereby classifying according to the motor subsystems.

\section{ACD in Relation to Site of Damage and Motor Impairment}

Cerebellar Lesions. Speech features of cerebellar dysarthria in adults are described in Table 1. In children. cerebellar tumor resection may cause a syndrome of mutism with subsequent dysarthria: MSD. This clinical picture has been described in a greater number of children than has ACD associated with any other lesion site. The primary site of lesion is the cerebellar vermis, but the tumor and the effects of surgery may affect adjacent structures.

Most studies refer to type and severity of dysarthria in the acute stage after recovery from mutism. In 20 cases, speech was judged according to the Mayo Clinic List of speech features by experienced professionals or speech pathologists. These studies are presented in Table 2. All children with MSD \{11-23\} had severe limb and trunk atiaxia. "Slow articulation," "monotony," and "hoarse soft voice" were the most frequent speech abnormalities. Irregular articulatory breakdown and excess and equal stress resulting in scanning speech. which are most prominent in ataxic speech in adults (Table 1), were certainly not the hallmark of ACD in these children. Nagatani et al. [15] and Al Jarallah et al. [19] explicitly mentioned that speech was "not explosive nor scanning." van Dongen et al. [18] reported that the observed speech features did not fit into any specific cluster of deviant speech dimensions. In the course of improvement, there was marked dissociation between speech impairment and motor disability: The initially severe dysarthria recovered (almost) completely while ataxic motor impairment persisted in most children.

We could find only two reports on speech characteristics of ACD after cerebellar damage resulting from a different etiology (Table 3). Echenne et al. 124] reported swallowing difficulties, velar paralysis, and "dysphonic, hoarse speech" of short duration after two episodes of vomiting, headache, and dizziness (Table 3). Computed tomography scan demonstrated an area of decreased density in the lateral part of the left cerebellar hemisphere, caused by a filling defect of the distal portion of the basilar 


\begin{tabular}{|c|c|c|c|c|c|}
\hline Reference & $\begin{array}{l}\text { Patient } \\
\text { Sex/Age } \\
\text { (y) }\end{array}$ & Lesion Site & Motor Disorder & $\begin{array}{l}\text { lower } \\
\text { Cranial } \\
\text { Nerves }\end{array}$ & Speech Features \\
\hline Rekate et al. $\mid 1 \|$ & $\mathrm{F} / 8$ & Medial & Limb ataxia. $R$ paresis & $N$ & Slow, monotonous \\
\hline Volcan et al. $[12]$ & $F / 8$ & Medial & Trunk ataxia, $\mathbf{R}$ paresis & L VI paresis & Monotonous, monosyllabic \\
\hline Dietze and Mickle [13] & $\mathrm{M} / 7$ & $\mathrm{RH}$ and $\mathrm{I} . \mathrm{H}$ & Trunk atiaxia: & $\mathrm{N}$ & Sparse, slow, monotonous \\
\hline Ferrante et al. $|14|$ & $F / 5$ & Medial & Alaxic gait & $N$ & Scanning \\
\hline Nagatani et al..115] & $F / 4$ & Medial & Trunk allaxia & $N$ & $\begin{array}{l}\text { Slow, monotonous, not explosive } \\
\text { or scanning }\end{array}$ \\
\hline Catsman-Berrevoets et al. $|16|$ & $\mathrm{M} / 6$ & Medial & $\begin{array}{l}\text { Trunk and limb ataxia, } R \\
\text { paresis }\end{array}$ & $\begin{array}{l}\text { L/R XII } \\
\text { paresis }\end{array}$ & $\begin{array}{l}\text { Audible respiration, incoordination } \\
\text { of respiration and speech, hoarse. } \\
\text { nasal, consonant distorsion }\end{array}$ \\
\hline Herb and Thyen [17] & $M / 9$ & Media! & $\mathrm{R}$ ataxia. $\mathrm{R}$ paresis & $\begin{array}{l}\text { L/R VII } \\
\text { paresis }\end{array}$ & $\begin{array}{l}\text { Aphonia, slow articulation. no } \\
\text { synchronization of articulation and } \\
\text { phonation }\end{array}$ \\
\hline van Dongen et al. [18] & $\mathrm{F} / \mathrm{8}$ & Medial & Trunk and limb ataxia & $\begin{array}{l}\text { L VII } \\
\text { paresis. L } \\
\text { XII paresis }\end{array}$ & $\begin{array}{l}\text { Alternating loudness, flat vowels. } \\
\text { consonant cluster reduction }\end{array}$ \\
\hline van Dongen et al. $118 \mathrm{j}$ & $\mathrm{M} / \mathrm{8}$ & Medial & $\begin{array}{l}\text { Trunk and limb ataxia. } \mathrm{R} \\
\text { paresis }\end{array}$ & L. XII paresis & $\begin{array}{l}\text { Hoarse, soft voice, omission on of } \\
\text { tinal sounds }\end{array}$ \\
\hline van Dongen et al. $|18|$ & M/5 & Medial & Trunk and timb ataxia & XII weakness & $\begin{array}{l}\text { Slow rate, strained-strangled voice. } \\
\text { syllabification }\end{array}$ \\
\hline Al Jarallah et al. $\mid 191$ & $F / 9$ & Medial & $\mathrm{N}$ & $\mathrm{N}$ & Slow. monotonous. $n$ ox explosive \\
\hline Crutchfield et al. $\{20\}$ & $\mathrm{M} / 7$ & Medial & Upper limb and trunk ataxia & $\mathrm{N}$ & Whispering \\
\hline Kin oma et al. $|21|$ & $M / 5$ & Medial & L hemiparesis & L VII pares:; & Slow, weak. monosyllabic \\
\hline Kingna et al. $\mid 2\} \mid$ & $M / 9$ & Fourth ventricle & $\mathrm{R}$ ataxia & NR & Slow speech rate \\
\hline Pollact et al $\{22\}$ & $\mathrm{M} / 16$ & Medial & L paresis & $\mathrm{N}$ & High-pitched nasal vuice \\
\hline Pollack at al. [22] & $M / 9$ & $\begin{array}{l}\text { Medial plus } \\
\text { fourth ventricle }\end{array}$ & $L$ ataxia & L Vl paresis & High-pitched voice \\
\hline Pollack et a 1 . 122] & $F / 6$ & $\begin{array}{l}\text { Medial plus } \\
\text { fourth ventricle }\end{array}$ & $R$ ataxia & $\mathrm{N}$ & Whispering. monosyllahic slow \\
\hline Asamoto et al. $\mid 2\} \mid$ & $\mathrm{F} / 8$ & Meciial & Dysmetria & $\mathrm{N}$ & $\begin{array}{l}\text { Monotonous, monosyliabic. } \\
\text { scanning }\end{array}$ \\
\hline \multicolumn{6}{|l|}{ Ahbreviations: } \\
\hline $\mathbf{F} \quad=$ Fcmalc & & & & & \\
\hline$H=$ Hemisphere & & & & & \\
\hline$=$ Left & & & & & \\
\hline $\mathrm{M}=$ Malc & & & & & \\
\hline MSD $=$ Mutism with sub squ & t dysarthria & & & & \\
\hline $\mathrm{N}=$ Normal & & & & & \\
\hline NR ... Not reported & & & & & \\
\hline $\mathrm{R}=$ Right & & & & & \\
\hline
\end{tabular}

artery. Dietze and Mickle 113 , observed ACD after the resection of a cerebellar arteriovinous malformation, but the features did not resemble those of adult dysarthria after cerebellar lesions (Table 3).
We conclude that dysarthria subsequent to a mute phase after cerebellar tumor resection is frequently characterized by slow speech rate, monotony, and hoarse soft voice. Excess and equal stress. distinctive for ataxic dysarthria in

Table 3. Clinical data of children with cerebetiar lesions

\begin{tabular}{|c|c|c|c|c|c|}
\hline Reference & $\begin{array}{l}\text { Patient } \\
\text { Sex/Age } \\
\text { (y) }\end{array}$ & tiology & Motor Disorder & $\begin{array}{c}\text { Lower Cranial } \\
\text { Nerves }\end{array}$ & Speech Features \\
\hline Echenne et al. $|24|$ & $\mathrm{M} / 9$ & Infarction L cirebellar $\mathrm{H}$ & $\begin{array}{l}\mathrm{L} \text { hemichorea and } \\
\text { ataxia. } \mathrm{R} \text { paresis }\end{array}$ & $\mathrm{IX} / \mathrm{X}$ paresis & $\begin{array}{l}\text { Dysphonia. } \\
\text { hoarseness }\end{array}$ \\
\hline Dietze and Mickle $\mid 13\}$ & $F / 15$ & $\begin{array}{l}\text { Resection of arten iovenous } \\
\text { malformation } R \text { and } L \\
\text { cerebellar } H\end{array}$ & $\begin{array}{l}\text { Diffuse hypotonia. } \\
\text { bilateral and } \\
\text { truncal ataxia }\end{array}$ & $N$ & $\begin{array}{l}\text { Monomonous. } \\
\text { labored and } \\
\text { bradykinetic }\end{array}$ \\
\hline
\end{tabular}

f.bbreviations:

Same as in Table 2 . 


\begin{tabular}{|c|c|c|c|c|c|}
\hline Reference & $\begin{array}{c}\text { Patient } \\
\text { Sex/Age } \\
\text { (y) }\end{array}$ & Etiology & Motor Disorder & $\begin{array}{c}\text { Lower Cranial } \\
\text { Nerves }\end{array}$ & Speech Features \\
\hline Bak et al. $[25]$ & $\mathrm{M} / 6$ & Infarct $L$ posterior thalamus & L paresis & $\begin{array}{l}\text { L. VII. L IX/X. } \\
\text { L XII pareses }\end{array}$ & $\begin{array}{l}\text { Imprecise consonants, distorted } \\
\text { vowels, hypernasality, breathy } \\
\text { voice, harsh voice, monopitch, } \\
\text { mono-loudness }\end{array}$ \\
\hline $\begin{array}{l}\text { van Dongen et al. } \\
\text { [18] }\end{array}$ & $\mathrm{M} / 10$ & Fourteenth ventricle tumor & Mild limb ataxia & $\begin{array}{l}\mathrm{R} I X, \mathrm{X}, \text { and } \\
\text { XII paresis }\end{array}$ & Very soft voice \\
\hline $\begin{array}{l}\text { van Dongen et al. } \\
{[18]}\end{array}$ & $F / 4$ & $\begin{array}{l}\text { Posterior fossa tumor } \\
\text { anterior to the basilar artery }\end{array}$ & Flaccid tetraparalysis & $\mathrm{N}$ & $\begin{array}{l}\text { Whispering a limited number } \\
\text { of words }\end{array}$ \\
\hline Frim and Ogilvy [26] & $F / 8$ & $\begin{array}{l}\text { Surgical resection of } \\
\text { pontine cavernous } \\
\text { hemangioma }\end{array}$ & L paresis & L VII weakness & $\begin{array}{l}\text { Dysarthria of speech prosody } \\
\text { and rhythm }\end{array}$ \\
\hline
\end{tabular}

adults, were evident in only two cases (Table 1). In MSD, dysarthria usually disappears, whereas ataxia persists in most children for a considerable time. The results of the cited studies do not sufficiently support the current practice of labeling dysarthria in MSD ataxic. Neither did cerebellar les:ons of a different etiology cause speech features resembling ataxic dysarthria in adults.

Brainstem Lesions. Damage to the nuclei of the lower cranial ierves in the bulbar region of the brainstem may result in flaccid bulbar dysarthria. Prominent speech fea- tures of adult bulbar dysarthria $\{1,2\}$ are described in Table 1.

For the purpose of the present study, we excluded diseases affecting the (peripheral) neuromuscular junction or the muscles such as in myasthenia gravis, muscular dystrophy, or Guillain-Barré syndrome.

We reviewed studies presenting neuroradiologic evidence of brainstem lesions associated with ACD (Table 4). Strokes due to vertebral artery occlusion, a well-known entity in adults, are rare in the pediatric population [27,28]. Older

Table 5. Characteristics of children with basal ganglia lesions

\begin{tabular}{|c|c|c|c|c|c|}
\hline Reference & $\begin{array}{c}\text { Patient } \\
\text { Sex/Age } \\
\text { (y) }\end{array}$ & litiology & $\begin{array}{l}\text { Motor } \\
\text { Disorder }\end{array}$ & $\begin{array}{l}\text { Lower } \\
\text { Cranial } \\
\text { Nerves }\end{array}$ & Speech Features \\
\hline $\begin{array}{l}\text { Murdech et al. } \\
{[3.3\}}\end{array}$ & $M / 13$ & $\begin{array}{l}\text { Postanoxic bilateral } \\
\text { striato-capsular } \\
\text { lesions }\end{array}$ & $\begin{array}{l}\text { Clinical fiatures } \\
\text { of parkinsonism }\end{array}$ & $\begin{array}{l}\text { L/R VII } \\
\text { paresis }\end{array}$ & $\begin{array}{l}\text { At } 7 \text { wk. impairment of } \\
\text { hilabial consonants, slow } \\
\text { rate, and labored speech: at } \\
10 \text { wk. difficulty controlling } \\
\text { speech rate and impaired } \\
\text { initiation of speech }\end{array}$ \\
\hline $\begin{array}{l}\text { Al-Mateen et al. } \\
|.34|\end{array}$ & $F / 9$ & $\begin{array}{l}\text { Inflammatory } \\
\text { lesions of caudate } \\
\text { nucleus, putamen. } \\
\text { and globus pallidus }\end{array}$ & $\begin{array}{l}\text { Dystonia. } \\
\text { choreiform } \\
\text { movements of } \\
\text { the extremities }\end{array}$ & NR & $\begin{array}{l}\text { Hypophonic } \\
\text { incomprehensible utterances }\end{array}$ \\
\hline $\begin{array}{l}\text { Pranzatelli et al. } \\
|.35|\end{array}$ & $F / 12$ & Anaphylactic shock & $\begin{array}{l}\text { Dystonia. } \\
\text { bradykinesia. } \\
\text { rigidity }\end{array}$ & NR & $\begin{array}{l}\text { After mutism. hypophonic } \\
\text { speech }\end{array}$ \\
\hline $\begin{array}{l}\text { Pranzatelli et al. } \\
\qquad .35 \mid\end{array}$ & $M / 14$ & Head trauma & $\begin{array}{l}\text { Dystonia. } \\
\text { hemiballismus, } \\
\text { bradykinesia, } \\
\text { rigidity }\end{array}$ & NR & Stuttering speech \\
\hline Aram et al. $|36|$ & $\mathrm{F} / 8$ & $\begin{array}{l}\text { Vascular lesions } L . \\
\text { globus pallidus. } \\
\text { putamen, posterior } \\
\text { part of internal } \\
\text { capsule, caudate }\end{array}$ & $\mathrm{R}$ paresis & N & $\begin{array}{l}\text { Consonant cluster reduction, } \\
\text { consonant omissions }\end{array}$ \\
\hline
\end{tabular}

Abbreviations:

Same as in Table 2 . 
studies reported "slow", "slurred", or "dragged" speech $[27,29]$. One study reports speech features after occlusion of the basilar artery in a 6-year-old boy [25]. ACD in this child was associated with bulbar palsy. The speech pattern resembled bulbar dysarthria in adults. Initially, computed tomography scan showed no abnormalities, but some weeks later, a small infarct in the left thalamus was demonstrated.

The clinical picture of mutism and subsequent dysarthria, frequently labeled cerebellar, has also been reported after surgical resection of a cavernous hemangioma of the right pons at the level of the middle cerebellar peduncle [26] (Table 4). "Impairment of prosody and rhythm of speech" was labeled as "cerebellar" dysarthria.

Two children of a series of children with posterior fossa tumor did not manifest mutism but did have mild speech problems after surgery [18] (Table 4). A 10-year-old boy spoke with a very "soft voice" 2 days after extubation after undergoing resection of a tumor in the fourth ventricle invading the right cerebellar hemisphere and the right cerebellar peduncle. A 4-year-old girl answered questions by silently moving her lips and whispered a limited number of words after undergoing resection of a meningioma situated anterior to the basilar artery.

In adults, speech deficits resulting from bilateral thalamic lesions have been documented by Ackermann et al. [30]. In children, little is known about speech deficits resulting from thalamic lesions. Garg and DeMyer [31] presented the clinical features of 6 children with thalamic strokes, of whom one child had "slurred speech". Parker et al. [32\} also reported "slurred speech" after infarction in the left thalamus associated with mycoplasma infection in an 8-year-old girl, but no further details on the speech features were described.

In one case study [25], a cluster of deviant speech leatures after brainstem lesion, with clinical signs of bulbar palsy resembling flaccid bulbar dysarthria in adults, was reported. Impairment of prosody was reported after resection of a cavernous hemangioma of the pons [26].

Basal Ganglia Lesions. In adults, movement disorders associated with basal ganglia lesions fall into two categories with opposite signs: hypokinesia and muscle rigidity, respectively, hyperkinesia with choreatic or dystonic movements. These two clinical entities are well recognized in speech as hypokinetic and hyperkinetic dysarthria $[1,2\}$ (Table 1).

In children, pure hypokinetic or hyperkinetic movement disorders seldom occur. More often, there is a mixed extrapyramidal syndrome. Characteristics of children with basal ganglia lesions and associated speech features are listed in Table 5.

Murdoch et al. 133| reported a 13-year-old boy with posthypoxic hypokinetic movement disorder. Detailed speech analysis during a long follow-up period after a mute phase revealed the following speech features: "difficulty in controlling speech rate within a phrase," and "increase of speech rate within a sentence" (Table 5). These features were labelled hypokinetic dysarthria be- cause they are highly specific for adult patients with parkinsonism and do not occur in any other dysarthria type.

We found one case of ACD associated with hyperkinetic dystonic and choreiform movement disorder [34] (Table 5). Al-Mateen et al. [34] described a 9-year-old gir] with encephalitis due to mycoplasma infection. Magnetic resonance imaging showed areas of low-signal intensity involving the caudate, putamen, and globus pallidus. One month after disease onset, she had dystonic posturing of the right foot, dyskinetic movements of the face, and choreiform movements of the extremities. Speech was "hypophonic with incomprehensible vocal utterances." In the course of improvement, a marked discrepancy between severity of speech deficit and movement disorder was observed: 18 months after onset of the illness, "she was still unable to initiate speech without cuing but she could run, skip, and climb" [34].

Mixed hyper- and hypokinetic movement disorder associated with ACD has been described in detail in two cases [35] (Table 5). Pranzatelli et al. [35] examined 6 patients with extrapyramidal movement disorders due to various etiologies. Abnormal speech was present in all children, of whom 3 were initially mute. Case 1, a 12-year-old girl, virtually unable to move or speak, improved with medication and produced "hypophonic speech" (Table 5). Case 2, a 14-year-old boy. with bradykinesia and rigidity, also exhibited writhing hemiballistic movements of the left hand. This mixed extrapyramidal movement disorder was associated with "stuttering speech" (Table 5).

in one case, basal ganglia lesions were associated with ACD but not with extrapyramidal movement disorder. After sustaining a left-sided infarction, involving the globus pallidus, the putamen, the body of the caudate, and the posterior limb of the internal capsule. Case 2 of Aram et al. [36] (Table 5) exhibited dysarthria. The patient manifested right-sided hemiparesis, but no signs of extrapyramidal movement disorder. Speech was mildly affected, mainly in articulation. Silverstein and Brunberg 137| reported mild dysarthria with rapid resolution in 2 children with postvaricella basal ganglia infarction. One child presented with hemiparesis and hemichorea, associated with "slurred speech".

The review shows some resemblance of such disorders to that in the adult model. In children with extrapyramidal movement disorders, dysarthria may be characterized by hypophonia, stuttering, and difficulty in controlling speech rate, which are highly specific for hypokinetic dysarthria in adults (Table 1). Moreover, the degree of movement disorder appears to correlate with the speech impairment except for one case [34]. Both may subside with medication, which substantiates the correlation of the extrapyramidal movement disorder with the severity of the dysarthria. 
Cerebral Cortical Lesions: Anterior Opercular Syndrome. Functional impairment or structural damage to the anterior or part of the insula, the operculum, leads to the well-studied opercular syndrome with uniform findings. Its most significant hallmark is loss of voluntary control of orofacial musculature with drooling, anarthria (i.e., speechlessness as the most severe form of dysarthria), and aphonia. Mental status is preserved and language comprehension is intact. There is no emotional lability. Patients cannot produce voluntary orofacial movements on request, whereas patients may yawn, laugh, or be able to perform complex movements spontaneously, such as blowing out a match [38]. In adults, the opercular syndrome is most often attributable to cerebral ischemia. The major deficits, dysphagia and anarthria, are unlikely to be reversible since no full recovery has been documented [38].

In children, various etiologies may cause the (rare) opercular syndrome. Because of its uniform clinical picture, data are not summarized in Table 1 to 6 . Deonna et al. $[39 \mid$ reported oromotor and speech disturbances as a focal epileptic manifestation. They examined 3 children diagnosed with benign partial epilepsy with rolandic spikes. As a result of recurring seizures around the sylvian area, "speech arrest" of short duration, "slow speech rate." "poor prosody," and "imprecise articulation" occurred as prolonged or postictal deficits, sometimes resembling an incomplete anterior opercular syndrome.

Shafrir and Prensky [40] observed opercular syndrome of epileptic origin in a child with recurrent prolonged episodes of severe oral apraxia. dysarthria, and drooling. During these episodes, there was an increase in right temporal spikes and appearance of generalized spikes. polyspikes, and slow wave discharges. Remissions were associated with improvement evident in the electroencephalogram, which either showed right temporal focus or was lree of epileptiform activity [40].

Continuous partial seizures in the rolandic areas for a prolonged time caused extreme drooling, impairment of tongue function, and "slurred speech" in 2 children with preexistent benign partial epilepsy with rolandic spikes. Speech recovered fully after adequate treatment of the seizures [41].

Other etiologies of opercular syndrome have been described in children. A 13-year-old boy 142] sustained biopercular infarctions after vasculitis resulting from a scorpion bite. The mutism lasted for months, after which he was able to laugh and cough and produce a few isolated vowels.

Massive infarctions in both opercula after tuberculous meningitis also caused opercular syndrome in a 3-year-old boy, who became verbally mute and aphonic, with his mouth constantly open and dribbling saliva [43]. One year later, he had regained the ability to articulate simple words. The patient of Prats et al. [44] who manifested opercular syndrome after herpes simplex encephalitis remained completely mute. Recovery from opercular syn- drome after infectious disease was also poor in 2 other children [45]. At follow-up after 2 years, Case 1 was able to speak with "impaired articulation" and "nasal speech." At onset, Case 2, a 24-month-old girl, had complete absence of speech and of all voluntary movements of jaw, lips, and tongue. Two years later, she had not regained any speech except for sounds and "a few and poorly articulated words" [45].

On an ictal or postictal basis, functional impairment of the anterior opercula interferes with orofacial musculature and speech. The mode of onset, relapses, and evolution show various patterns [39]. Outcome is favorable once the epilepsy is adequately treated.

After structural lesions, the clinical picture is similar to that in adults. The prognosis is poor, as is the case in adults: Patients remain mute for a long time and rarely regain speech. Speech features have therefore been incompletely analyzed.

Other Cerebral Contical and Internal Capsule Lesions. Deviant speech features in adults with spastic dysarthria, detected after cerebral cortical and internal capsule lesions, are presented in Table 1. Bilateral damage may result in persistent speech impairment in adults. Accompanying neurologic deficits consist of a pyramidal syndrome on one or both sides.

In children, dysarthria without aphasia or verbal apraxia [8-10] resulting from bilateral cerebral hemisphere lesions not located in the opercula have rarely been documented. Data are not summarized in Tables 1 to 6 because we could find only one case that fits our inclusion criteria [46]. "Stuttering-like speech" was noted in this 27 -month-old child with multiple infarctions in the periventricular white matter, 14 months after a subcortical infarction in the left basal ganglia that extended into the cortex |46|. Her stutter, Wich lasted 7 weeks, affected mainly the initial phonemes. and speech was "hypophonic."

Unilateral hemisphere lesions, on the other hand, have been reported to cause ACD, but descriptions of speech features have been less specific. After varicella infection, a 9-year-old boy sustained a left cerebral infarction involving the internal capsule and the caudate nucleus. He became dysarthric and developed rightsided central facial palsy and right-sided hemiplegia affecting the upper limb. All neurologic features resolved completely within hours [47].

"Slurred speech" and hemiparesis of the right arm and leg were the signs in a 6-year-old boy who sustained a small left middle cerebral artery ischemic infarction extending into the subcortical white malter. His clinical status demonstrated rapid improvement with complete recovery after 3 months $[48]$.

Reports of ACD subsequent to circumscribed cerebral hemisphere lesions are scarce. Because unilateral lesions may lead to transient ACD, studies have not focused on its specific features. Bilateral nonopercular hemisphere lesions associated with dysarthria, frequent in adults, were 
documented in only 1 child, who developed stuttering-like speech impairment [46]. To our knowledge, dysarthria without aphasia or verbal apraxia, resulting from acquired nonopercular cortical lesions and resembling spastic, pseudobulbar dysarthria in adults has not been described in children.

\section{The Presence of ACD in Clinical Management}

We studied the relationship between ACD on the one hand, and motor disorder on the other, according to the clinical features or the neuroradiologic evidence of lesion site. The second aim of our study was to review studies demonstrating that the occurrence of dysarthria may be a marker of clinical deterioration or that recovery from dysarthria may herald clinical improvement. Analysis of dysarthria may therefore be of importance for clinical management.

Reitman et al. [49] analyzed speech deficits in survivors of Reye's syndrome. Twenty-six of the 43 examined children were dysarthric, aphonia being the most common features. In 4 children, the dysarthria was the predominant handicap at 12 months follow-up. The investigators concluded that in rehabilitation of Reye's syndrome, one should anticipate the occurrence of speech problems.

Intrathecal methotrexate (MTX) treatment is an essential part of central nervous system prophylaxis for leukemia in children. Neurologic complications due to neurotoxic reactions may follow such therapy $[50,51]$. Yim et al. [51] observed severe hemiparesis and brief but profound dysarthria of sudden onset in 2 children after they received intrathecal MTX treatment. Initially, these signs were considered part of an MTX-induced encephalopathy. Later, computed tomography and magnetic resonance imaging scans showed ischemic structural lesions in the cerebral hemisphere in both children. This clinical picture. in which the profound dysarthria was prominent. maly be an indication of ischemic brain lesions and differs from the clinical picture of MTX encephalopathy.

The presence of dysarthria appears to have a prognostic value in cases of thalamotomy performed 10 alleviate the disabling tremor that may occur in posttraumatic midbrain syndrome. In two patient groups (aged 10 to 29 years) $[52,53]$, thalamotomy alleviated the tremor. However, the preexistent posttraumatic dysarthria tended to worsen postoperatively. In both studies $[52,53]$, worsening of the dysar hria was considered a major limitation to the surgical intervention and the existence of a preoperative dysarthria was considered a contraindication for thalamotomy.

van Dongen et al. [54] analyzed dysarthria speech features in children with supranuclear or peripheral facial palsy. (Because the lesions were diffuse, we did not include this study in the previous text.) In the present context, we note that severity of dysarthria was analyzed in relation to neurologic deficits. In patients with supranuclear palsy, recovery from severe dysar- thria to intelligible speech preceded improvement in other motor functions.

Dysarthria may occur as an initial feature of rare structural lesions during MTX treatment. It may signal structural brain damage as a result of ischemia. As such, its sudden onset as a focal neurologic feature differs from the neurotoxic reactions in MTX encephalopathy. Recognition of the sudden onset of dysarthric speech is therefore of diagnostic significance and contributes to clinical management [51]. In thalamotomy performed to alleviate posttraumatic tremor, the dysarthria may worsen despite improvement in other motor function. The presence of dysarthria constitutes a major contraindication for thalamotomy [52,53]. Recovery from dysarthria may precede neurologic improvement [54].

\section{Discussion}

Our main aim in the present study was to provide a survey of speech features in ACD and to compare them with the adult types of dysarthria $[1,2]$. In children. dysarthria associated with cerebellar tumor resection $(\mathrm{Ta}-$ ble 2) has received more attention than dysarthria associated with any other type of lesion. In this group, speech was frequently characterized by slow speech rate and monotony. These features are not distinctive of ataxic dysarthria because they may occur in other dysarthria types. Excess and equal stress-scanning speech-considered the hallmark of ataxic dysarthria in adults and not occurring in any other dysarthria type $[1,2]$, was rarely observed even in children with severe dysarthria. We found one other case of ACD resulting after cerebellar stroke [24] that did not show typical ataxic speech features either. Therefore in children, cerebellar lesions, particularly tumor resection, may cause speech deficits not resembling ataxic dysarthria in adults. As yet, the validity of the adult model for children with cerebellar lesions has not been sufficiently proven.

In other patient groups with lesions in different areas of the brain, grossly classified on the basis of neuroradiologic or neurophysiologic similarities, clusters of deviant specer features that would be specific for each group have not emerged either. An exception appears to be the speech features associated with basal ganglia lesions [33-37]. Features that are not reported in other dysarthria types. such as short rushes of speech, difficulty in controlling speech rate (festination), and stuttering were also recorded in children (Table 1), which suggests that lesions involving the basal ganglia may cause speech deviancies that resemble dysarthria in adults with similar movement disorders.

We had two reasons to take the adult model of clusters of speech features mirroring the motor impairment as a starting point [1,2]. First, cited studies comprise the largest groups of dysarthric adults ever investigated. The typology of dysarthrias $[1,2]$ has been applied universally to label deviant speech, in adults as well as in children. Second, an 
equivalent model of motor speech disorders for children is lacking. Therefore, Murdoch et al. [55] claim that although it is difficult to apply models and theories developed for adults to children it appears to be appropriate to use the ciassification system of Darley et al. [1] to describe the equivalent speech disorders in children until more information becomes available to refute its appropriateness.

In light of this, it is of importance to stress that the quality of nonspeech movements, articulation, velopharyngeal function, and orofacial musculature change during development [56,57]. Moreover, normal speech in children may reveal features such as strained voice, breathiness, and hyponasality that are considered pathologic in adult speech [58]. Developmental norms are well known to speech pathologists working with children developmentally impaired in speech/language but may be poorly recognized within clinical circles. We could find only one study addressing the discrimination of developmental and acquired dysarthric aspects of articulation in acquired cerebellar lesions [59], but this study did not fit our inclusion criteria. As to the second aim of our review, the available literature shows that analysis of dysarthria may play a crucial role in the recognition of clinical changes.

All observations reviewed in the present study are based on single case studies, which illustrates the fact that dysarthria has been treated as a Cinderella [60], in children even more so than in adults. As yet, the study of ACD is still in its infancy, as was true of the study of acquired childhood aphasia in the late 1970s. Until then, studies of aphasia in children had focused mainly on the fundamental differences between the neurology of language in children and adults $|6| \mid$. More recently, systematic studies of recovery from acquired childhood aphasia and of lesion analyses $|8|$ demonstrated that correlations between aphasia type and lesion localization parallel those in adults 18,611. As to ACD, it is not yet possible to predict what systematic analyses of speech features and anatomoclinical correlation studies will teach us about the similarity and differences between dysarthria in children and in adults. The current knowledge of ACD, reviewed herein, indicates that $A C D$ requires its own classification, developed through detailed analysis of speech features in dysarthric children.

\section{References}

[1] Darley FL. Aronson AE. Brown JR. Differential diagnostic patterns of dysarthria. J Speech Hear Res 1969:12:246-69.

[2] Darley FL. Aronson AE, Brown JR. Motor Speech Disorders. Philadelphia: W.B. Saunders, 1975.

[3] Hirose H. Pathophysiology of motor speech disorders (dysarthria). Folia Phoniatr 1986:38:61-88.

[4] Kluin KJ. Gilman S, Markel DS, Koeppe RA, Rosenthal G, Junck L. Speech disorders in olivopontocerebellar atrophy correlate with positron emission tomography findings. Ann Neurol 1988:23:547-54.

[5] Ackermann H. Vogel M. Petersen D. Poremba M. Speech deficits in ischaemic cerebellar lesions. J Neurol 1992:239:223-7.

[6] Kluin KJ. Foster NL. Berent S. Gilman S. Perceptual analysis of speech disorders in progressive supranuclear palsy. Neurology 1993:43: 563-6.

[7] Enderby P. Relationships between dysarthric groups. Br J Commun Dis 1986;21:189-97.

[8] Paquier PF, Van Dongen HR. Review of research on the clinical presentation of acquired childhood aphasia. Acta Neurol Scand 1996:93: 428-36.

[9] Square PA, Aronson AE, Hyman E. Case study of the redevelopment of motor speech control following acquired brain damage in early childhood. Am J Speech Lang Pathol 1994:3:67-80.

[10] Deonna T, Chevrie C, Hornung E. Childhood epileptic speech disorder: prolonged, isolated deficit of prosodic features. Dev Med Child Neurol 1987;29:96-109.

[11] Rekate HL, Grubb RL, Aram DM, Hahn JF, Ratcheson RA. Muteness of cerebellar origin. Arch Neurol 1985;42:697-8.

[12] Volcan I, Cole GP, Johnston K. A case of muteness of cerebellar origin. Arch Neurol 1986;43:313-4.

[13] Dietze D, Mickle JP. Cerebellar mutism after posterior fossa surgery. Pediatr Neurol 1990:4:228-30.

[14] Ferrante L, Mastronardi L, Acqui M, Fortuna A. Mutism after posterior fossa surgery. J Neurosurg 1990:72:959-63.

[15] Nagatani K. Waga S, Nakagawa $Y$. Mutism after removal of a vermian medulloblastoma: Cerehellar mutism. Surg Neurol 1991;36: $307-9$.

[16] Catsman-Berrevoets CE, Van Dongen HR. Zwetsloot CP. Transient loss of speech followed by dysarthria after removal of posterior fossa tumour. Dev Med Child Neurol 1992;34: 11(1)2-17.

[17] Herb E. Thyen U. Mutism after cerebellar medulioblastoma surgery. Neuropediatrics 1992;23:144-6.

[18] van Dongen HR, Catsman-Berrevoets $C E$, van Mourik $M$. The syndrome of "cerebellar" mutism and subsequent dysarthria. Neurology 1994:44:2040-6.

[19] Al-Jarallah A, Cook JD, Gascon G, Kanaan I, Sigueira E. Transient mutism following posterior fossa surgery in children. J Surg Oncol 1994:55:126-31.

[20] Crutchfield JS, Sawaya R, Meyers CA, Moore BD. Postoperative mutism in neurosurgery. I Neurosurg 1994:81:115-21.

[21] Kingma A. Mooij JJA, Metzemaekers JDM, Leeuw JA. Transient mutism and speech disorders after posterior fossa surgery in children with brain tumors. Acta Neurochir (Wien) 1994:131:74-9.

[22] Pollack IF. Polinko P. Albright AL. Towhin R. Fitz C. Mutism and pseudobulbar symptoms after resection of posterior fossa tumors in children: Incidence and pathophysiology. Neurosurgery 1995:37:885-93.

[23] Asamoto M. Ho H. Suzuki N. Oiwa Y. Saito K. Haraoka J. Transient mutism after posterior fossal surgery. Child Nerv Syst 1994; 10:275-8.

[24] Echenne B. Gras M. Astruc J. Castan P. Brunel D. Vertebrobasilar arterial occlusion in childhood-report of a case and review of the literature. Brain Dev 1983:5:577-81

[25] Bak E, van Dongen HR. Arts WFM. The analysis of acquired dysarthria in childhood. Dev Med Child Neurol 1983:25:81-94.

[26] Frim DM. Ogilvy CS. Mutism and cerebellar dysarthria after brainstem surgery: Case report. Neurosurgery 1995:36:854-7.

[27] Pascual-Castroviejo I. Pascual-Pascual J1, Mulas F, Roche MC. Tendero A. Bilateral obstruction of the vertebral arteries in a three-year-old child. Dev Med Child Neurol 1977;19:232-8.

[28] Garg BP, Ottinger CJ, Smith RR, Fishman MA. Strokes in children due to vertebral artery trauma. Neurology 1993:43:2555-8.

[29] Singer WD. Haller JS. Wolpert SM. Occlusive vertebrobasilar artery disease associated with cervical spine anomaly. Am J Dis Child 1975:129:492-5.

[30] Ackerman H. Ziegler W. Petersen D. Dysarthria in hilateral thalamic infarction. J Neurol 1993:240:357-62.

[31] Garg BP. DeMyer WE. Ischemic thalamic infarction in children: Clinical presentation. etiology, and outcome. Pediatr Ncurol 1995: 13:46-9.

[32] Parker P. Puck J. Fernandez. F. Cerebral infarction associated with Mycoplasma pneumoniale. Pediatrics 1981:67:373-5. 
[33] Murdoch BE, Chenery HJ, Kennedy M. Aphemia associated with bilateral striato-capsular lesions subsequent to cerebral anoxia. Brain Inj 1989;3:41-9.

[34] Al-Mateen M, Gibbs M, Dietrich R, Mitchell WG, Menkes JH. Encephalitis lethargica-like illness in a girl with mycoplasma infection. Neurology 1988:38:1155-8.

[35] Pranzatelli MR. Mott SH, Pavlakis SG, Conry JA. Tate ED. Clinical spectrum of secondary parkinsonism in childhood: A reversible disorder. Pediatr Neurol 1994:10:131-40.

[36] Aram DM. Rose DF. Rekate HL. Whitaker HA. Acquired capsular/striatal aphasia in childhood. Arch Neurol 1983;40:614-7.

[37] Silverstein FS, Brunberg JA. Postvaricella basal ganglia infarction in children. Am J Neuroradiol 1995;16:449-52.

[38] Weller M. Anterior opercular cortex lesions cause dissociated lower cranial nerve palsies and anarthria but no aphasia: Foix-ChavanyMarie syndrome and "automatic voluntary dissociation" revisited [Fditorial]. I Neurol 1993:240:199-208.

[39] Deonna TW, Roulet E, Fontan D, Marcoz JP. Speech and oromotor deficits of epileptic origin in benign partial epilepsy of childhood with rolandic spikes (BPERS). Relationship to the acquired aphasia-epilepsy syndrome. Neuropediatrics 1993:24:83-7.

[40] Shafrir Y, Prensky AL. Acquired epileptiform opercular syndrome: a second case report. review of the literature, and comparison to the Landau-Kleffner syndrome. Epilepsia 1995;36:1050-7.

[41] Fejerman N, Di Blasi AM. Status epilepticus of benign partial epilepsies in children: Report of two cases. Epilepsia 1987:28:351-5.

[42] Groswasser Z, Groswasser-Reider I. Korn C. Biopercular lesions and acquired mutism in a young patient. Brain Inj 1991:5:331-4.

[43] Moodley M, Bamber S. The operculum syndrome: An unusual complication of tuberculous meningitis. Dev Med Child Neurol 1990: 32:919-22.

[44] Prats JM. Garaizer C, Uterga JM, Urroz MJ. Operculum syndrome in childhood: A rare cause of persistent speech disturbance. Dev Med Child Neurol 1992;34:359-64.

[45] Van der Poel JC, Haenggli CA, Overweg-Plandsoen WCG. Operculum syndrome: unusual feature of herpes simplex encephalitis. Pediatr Neurol 1995;12:246-9.

[46] Nass R, Schreter B. Heier L. Acquired stuttering after a second stroke in a two-year-old. Dev Med Child Neurol 1994:36:70)-83.

[47] Tucciaroni L. Ballati G, Chiaramida N. Frangella F. Diamanti A. Cerebral infarction in a child. A case report. Padiatr Padol 1992:27: 101-4.
[48] Karoutas G. Karacostas D, Artemis N, Tsounis S, Dukidis A. Ischemic infarct in childhood secondary to internal carotid artery dissection. Report of a case. Funct Neurol 1989:4:287-91.

[49] Reitman MA, Casper J. Coplan J. Weiner LB, Kellman RM. Kanter RK. Motor disorders of voice and speech in Reye's syndrome survivors. Am J Dis Child 1984:138:1129-1131.

[50] Terheggen HG. Cerebrale Nebenwirkungen bei der Behandlung akuter Leukämien im Kindesalter. II. Die Methotrexat-induziente Ecephalopathie. Monatsschr Kinderhulkd 1978:126:696-701.

[51] Yim YS. Mahoney DH. Oshman DG. Hemiparesis and ischemic changes of the white matter after intrathecal therapy for children with acute lymphocytic leukemia. Cancer 1991;67:2058-61.

[52] Andrew J, Fowler CJ, Harrison MJG. Tremor after head injury and its treatment by stereotaxic surgery. J Neurol Neurosir Psychiatry 1982;45:815-9.

[53] Bullard DE, Nashold BS. Sterotaxic thalamotomy for treatment of posttraumatic movement disorders. I Neurosurg 1984;61:316-21.

[54] van Dongen HR, Arts WF, Youself-Bak E. Acquired dysarthria in childhood: An analysis of dysarthric fearures in relation to neurologic deficits. Neurology 1987;37:296-9.

[55] Murdoch BE. Ozanne AE, Cross JA. Acquired childhood disorders: dysarthria and apraxia. In: Murdoch BE, ed. Acquired neurological speech language disorder in childhood. London: Taylor and Francis, 1990:309.

[56] Robbins J. Klee T. Clinical assessment of oropharyngeal motor development in young children. J Speech Hear Disord 1987: 52:271-7.

[57] Qvarnström MJ, Jaroma SM. Laine MT. Changes in the peripheral speech mechanism of children from the age of 7 to 10 years Folia Phoniatr Logop 1994:46:193-202

[58] van Mourik M, Boon P. Paquier PF. Lormans A. van Dongen HR. Speech characteristics in children with congenital hemiplegia |Letter]. Acta Paediatr 1994:83:317-8.

[59] Murdoch BE, Hudson-Tennent LJ. Speech disorders in children treated for posterior fossa tumours: Alaxic and developmental features. Eur J Disord Commun 1994:29:379-97.

[60] Lebrun Y. Acquired dysarthria and dysfluency in adults. In: Lebrun Y, ed. From the Brain w) the Mouth. Dordrecht: Kluwer Academic Publishers, 1997:3.

|61) Rapin I. Acyuired aphasia in children |t:ditorial| I Child Neurol 1995:10:267-70). 